\title{
Enhancing the Critical Role of Malaysian Institute of Higher Education from Ivy League American Universities Research Culture Experiences
}

\author{
Hj. Kamaruzaman Jusoff (Corresponding author) \\ Tropical Forest Airborne Observatory (TropAIR) \\ Faculty of Forestry \\ Universiti Putra Malaysia \\ Serdang, 43400 Selangor. Malaysia
}

Tel: 60-3-8946-7176 E-mail: kamaruz@putra.upm.edu.my

Hjh. Siti Akmar Abu Samah

UiTM International Centre

WIEF-UiTM International Centre Building

Universiti Teknologi MARA

40450 Shah Alam, Selangor. MALAYSIA

Tel: 60-3-5544-4935 E-mail: sitiakma@salam.uitm.edu.my

Zaini Abdullah

Office of the Deputy Vice Chancellor (Research \& Innovation)/UiTM International Centre

Universiti Teknologi MARA

40450 Shah Alam, Selangor, MALAYSIA

Tel: 60-3-5544-4936Ｅ-mail: zabadu@salam.uitm.edu.my

This research is funded by Malaysian Academy of Sciences-Brain Gain Malaysia/Ministry of Science, Technology \& Innovation (sponsoring information)

\begin{abstract}
Emulation by example is an old adage that has been a pragmatic initiative in great endeavors. To create a dynamic research culture too requires revisiting eminent personality and renowned organization by which one can copy in order to establish credibility. This paper explores the practicality of the emulation activities that help to establish this dynamic research culture. Here, the writers address the American Ivy League universities as the exemplary institutions of knowledge that have been long established and that Malaysian institutions of higher education can continue to learn and adapt in order to continue achieving academic excellence, particularly in research practices. Pertinent areas covered are the current research and innovation taking place in the US tertiary education, nurturing academic entrepreneurship, the need for effective research leaders, creating talent pool for researchers' succession planning and internationalization, just to state a few. Simultaneously, establishing the research infrastructure and capacity is also another exploration that provides insights into the pertinent scope of academic establishment. This needs undivided attention by the leadership in the university. Through this sharing which is part of the experience acquired by the first author being an associate of an Ivy League institution, invaluable information in the paper can assist readers in understanding what is needed to establish a dynamic research culture for tertiary community.
\end{abstract}

Keywords: Research culture, Ivy League, Academic entrepreneurship, Talent pool, Research leadership, Tertiary, Academic excellence

\section{Introduction}

Yale University is ranked $2^{\text {nd }}$ Top World Ranking University by Times Higher Education Supplement (THES) Quacquarelli Symonds (QS) World University Rankings (WUR) in 2007 and 2008 and is one of American Ivy League universities. Significantly, it contributes to the major infrastructure and talent pool for academic excellence, industry-research collaborations, and internationalization networking. Hence, sharing this article should help tertiary community in Malaysia gain some insights on the interactions with a range of multi-agent stakeholders and help to contribute in transforming themselves into dynamic institutions. Hence, the efforts through an Ivy League experience can empower a dynamic research culture which will enhance the norms of academic scholarship, creating talent pool, 
team collaboration, discipline knowledge and participation in colloquia, journals and other peer review mechanisms. These are initiatives that will subsequently create ripples of research and innovation excellence.

\section{Research and innovation scenario in USA tertiary education}

Several cases are quoted below in order to learn from the challenges faced by the US tertiary community. These cases are indicators of vibrant academic entrepreneurship experience undergone by the United States academia in their very own research culture. A starting point is the experiences of Professor Emanuel Derman (http://www.ederman.com) of Columbia University, USA (ranked $10^{\text {th }}$. placing by THES in 2008). He had negative experiences as an "early career" researcher at Bell Laboratories by going through poor research management. However, the investment bank Goldman Sachs interacted by promoting a culture that valued academic rigour, business acumen, and conceptual skills and thus, has helped to provide a more satisfying experience (Derman, 2004).

Innovation advocates most often refer to information technology companies such as Google and Sun as exemplars of the pivotal role that universities play in new venture creation and industry or sectoral development (Vise, 2005; Vise \& Malseed, 2006; Hamel, 2007). Likewise are American giant companies such as Apple Incorporation, Roche, Satmetrix Systems, Proctor \& Gamble, Bristol-Meyers Squibb, where university research was "catalytic" and that followed the process below for new venture creation. Hence to quote Yale's 'Apple University', Apple Inc. has hired the Dean of the Business School, Yale University to head an educational initiative to be called Apple University. In another example, Procter \& Gamble, supports Yale University Collaboration for public health training throughout China.

Fruitful collaboration between Bristol-Myers Squibb and Yale Medical School fosters innovations in education and research. Continuing a partnership with the School of Medicine that was forged more than 30 years ago, the Bristol-Myers Squibb Co. has renewed its fellowship support for graduate students in the Combined Program in the Biological and Biomedical Sciences at Yale. This is commonly known as the BBS Program which has transformed the university's graduate education in the life sciences since its inception in 1996. Since then, Yale/Bristol-Myers Squibb Educational Alliance, has enabled Yale graduate students to gain exposure to private-sector biomedical research through summer rotations at BMS research and development campus in nearby Wallingford, Connecticut. More recently, at the School of Nursing's Program for the Advancement of Chronic Wound Care, an effort to devise clinical "best practices" for wound treatment, got under way in 2002 with support from the BMS Foundation and BMS's ConvaTec unit. In addition, with the guidance of Michael H. Merson, M.D., the Anna M.R. Lauder Professor of Public Health, the foundation has recruited Yale experts to evaluate the effectiveness of its Secure the Future initiative, which supports community-based initiatives in Southern and West Africa aimed at stemming the AIDS pandemic.

Recently, while at Yale, Dean Robert J. Alpern M.D., and Yale University President Richard C. Levin hosted BMS Chairman and CEO Peter R. Dolan, M.B.A., and other senior executives at a celebration of the alliance and other collaborations between BMS and Yale. A permanent plaque now honours the company's extraordinary contributions to medical research and education in Yale. Yale's President Levin said "It helped shape the direction and range of intellectual activity at the School of Medicine." For his part, BMS' Dolan offers a succinct assessment of the company's long relationship with Yale, "We are all better off". More notes and highlights of this success environment can be read from the latest 2008 monthly Yale Bulletin Research News and Yale Magazine.

Another leading provider of enterprise solutions for improving business loyalty and profitability, Satmetrix Systems announced that Yale University President Richard C. Levin has been appointed to its board of directors. Levin, the Frederick William Beheinecke Professor of Economics, was selected as the twenty-second president of Yale in 1993. Satmetrix Systems officials cited Levin's global business leadership, adroit stewardship as head of one of the world's premier universities, and his economics acumen as a much sought-after public policy advisor, renders him to be member of the board. Levin has articulated a compelling vision of Yale's fourth century as an international university by forging new alliances and the creation of programmes in emerging fields that include the Yale Center for the Study of Globalization (The former British premier, Mr. Tony Blair, was appointed as Visiting Professor/Fellow for Center for Faith \& Globalization); and the Yale Law School's China Law Center, a collaboration to increase understanding of China's legal system and assist China's legal reform process.

Exploring further, Lee Faulkner, as media director for Yale University's Digital Media Center for the Arts (DMCA), is always looking for the next cutting-edge way to connect art and technology. Lee found what he was looking for in Image Portal - a Web-based Lee Digital Asset Management (DAM) solution from NetXposure built specifically for the Apple Mac OS X platform. Now that Image Portal A/V is facilitating creation and collaboration among Yale's arts departments, the next step is to explore new ways of technology that can connect artists and art lovers outside the university and around the globe. Yale DMCA and NetXposure have initiated a project allowing arts departments of other universities to join Yale and engage in interactive, rich media messaging through flat-screen plasma display panels. 
In yet another dynamic emergence is financial engineering as a new sub-discipline in corporate finance that illustrates the "co-evolution" of new industry sectors, markets and universities. Cold War era science and technology projects created the demand in the 1960s and early 1970s for a cohort of mathematicians and physicists. However, by the mid-1980s, a geopolitical climate of detente and a decline in S\&T projects meant that many people in this cohort left government research laboratories and universities. Wall Street investment banks and hedge funds provided the catalyst, where these researchers were able to adapt their domain expertise to build financial models for derivatives, options and futures trading. By the late 1990s, these researchers had developed enough industry credibility to create and fund new departments at major universities in the United States. In a move that saw some practitioners come full circle, they left Wall Street to oversee these new teaching and research programmes (Lindsey \& Schachter 2007; Mehrling 2005; \& Derman 2004). Collectively, these approaches suggest that universities will continue to have a pivotal role in knowledge generation and transfer.

\section{Forging industry-academia partnerships}

In the last two decades a new entity has emerged on the campuses of America's research universities. This entity is known as the University-Industry Research Center or UIRC or in Malaysia, University Business Centers. Such centers composed of research groups led by renowned endowed Professors whose focus is on problems that have relevance to a particular sector of industry and these centers receive support from that industry. In 1990, more than 1,000 existed and involved more than 35,000 faculty researchers and 17,000 PhD students in the States. Many more exist today.

Strictly speaking, universities are not creating them. For example in Yale's Cooperative Research Centre (CRC), it was determined that individual faculty members, not university administrations, typically provide the impetus for the center. Motivations vary, but the need to create funding alternatives to declining or uncertain federal support is important, as is the desire to turn research efforts to a practical end. Additionally, nearly one quarter of all US PhD recipients in the sciences are finding positions in industry; so students are looking for training that is relevant to their career prospects.

\section{Nurture and promote academic entrepreneurship}

From the above observation, Malaysian universities need programmes with the conviction that educational structures reflect the increasingly fluid and interdisciplinary nature of biological science. Hence, such a culture is yearned for and Malaysian universities need this culture of cross discipline in Faculties, Centres or Institutes. Despite the efforts of thinkers, the Malaysian academics, for a long time have remained in the safe waters of premier, academic and scientific institutions. The thoughts of one scientist illustrate the following "Scientists are not supposed to think about the economic perspective on research and development projects. A scientist's work is supposed to provide scientific knowledge. Economics is quite another discipline..."(Ella, 2006) This mindset has to change.

This decade, which is all set to see a Malaysian academic-industry link boom, will belong to those who have the power to convert their dreams into reality. In other words, it will see the rise of the academic entrepreneur. These are shapers and movers who will move away from the safe waters of the laboratory and convert a patentable/testable research dream into a viable business proposition. Having just strings of medals from money biased organized research medal competition in the US, UK or Switzerland is not sufficient to nurture entrepreneurship.

Every Malaysian academia entrepreneur must thoroughly understand the grassroots features of any technology-based sector such as research, collaboration, infrastructure, and technology and commercialization capital and come up with an alternative business model to achieve success. An example of a spin-out is an airborne remote sensing company like the one first established four years ago in Universiti Putra Malaysia known as Aeroscan Precision (M) Sdn. Bhd. is progressing well till today. The details of academic entrepreneurship are available from the first author's book entitled "Academic Entrepreneurship: A Malaysian Research University Perspective" published this year (edited by the second author) by Universiti Teknologi MARA Publisher.

\section{Creating talent pool for researcher succession planning}

Great emphasis on the enhancement of research and innovation will definitely render for dynamic participation of all levels in the academia to play their role in the research arena (Kamaruzaman \& Siti Akmar, 2008b). Committed participation of every university citizenry in all aspects of academic excellence vis-a-vis international recognition has to be continuously enhanced. This aspiration requires the effort to generate excellence that begins from the fundamentals of leadership to create, generate and innovate. It is vital that research leaders apply leadership principles and insights into their own leadership styles to help generate cycles of academic activities, and hence, to attain the status of a research university.

In order to create such a research culture in the university, developing research leadership brings about positive outcomes based on a shared vision (Middlehurst, 1993). To do so, the creation of talent pool of potential research leaders can assist the university attain this daunting task. In Malaysian institutions of higher education, the crisis of succession planning occurs clearly in the public universities and colleges. Finding replacement for vacated position is not any easier when academic leaders have to retire or leave in absence due to emergency or taking a break (Zaini et al., 
2008). In an executing position to enhance research activities, similar scenario takes place. Suitable candidates to lead research activities need to possess leadership skills in both teaching and researching skills (Blanchard \& Miller, 2007).

Accordingly, in tandem with the government's mission and vision to enhance the standard and quality of higher education, university has pivotal role in establishing the country as an excellent research hub (Kamaruzaman \& Siti Akmar, 2008a). However, evidence reveals significant shortage in research leadership that can envisage the constantly changing research environment. With inadequate leadership skills, results and performance of the organisation are affected. The persistence of the occurring problem might have lagged the progress of research activity in Malaysian institutions.

The unique characteristics of academicians and the complexity in the career development in terms of research and its related area inside the higher education institutions in Malaysia need a special model of talent pool searching and succession planning. The system should accommodate and be in the favour of the needs of higher education institution to ascertain the flexibility of the academic performance while at the same time build core competencies for the institution to intensify research through competent research leadership. The standards and quality of higher education must be well maintained in order for a particular institution to be globally recognized (Brennan et al, 1997). Hence, a mark of standards and quality of higher education is the intensification of research activities with capable academia in the pool of leadership.

Good research leaders develop through never-ending process of self-study, education, training, and experience. Research leaders usually have the ability to lead research groups and to influence team members and other people and the activity of leading research. They are visible, accountable to the research team or staff and have a commitment to further the purpose and goals of research (Evans, 1999). Meanwhile, an innovative leader is someone who has the skills and creative followers to produce new products, processes or services. In short, good and innovative research leaders must be creative, visionary, imaginative, inspirational, insightful, foresighted and intuitional in leading their pool of researchers. It is not enough being innovative, research leaders must be emerging leaders too (Carucci, 2007).

Succession planning is a process that selects employees, develops their competencies, which then prepares them for future assignment in positions which require these competencies for effective performance in the organisation. The process involves understanding the institutions long-term goals and objectives, identifying the workforce's developmental needs and determining workforce trends and predictions. With good succession planning, which is commonly practiced in corporate organisation, it has been observed that academic institutions need to have this initiative to ensure effectiveness and smooth running of the institutions for new leadership roles as the need arises or one's term has ended (Boettcher \& Craven, 2008). There is a need for selection criteria for these talents to be readily 'groomed' for leadership role particularly in academic tasks such as research in institutions of higher education. A good succession planning can reduce the risk of one organization going into losing the target of the shared vision, that is, achieving the research university status and to ensure sustainability not only of the organization, but also the research culture within the organisation, as indicated through the significance of succession planning stated by Wolfred (2008).

The establishment of the succession plan and related models helps to nurture and strengthen the high performance culture in institutions of higher education via professional work force that exhibits self personality and professional personality, possession of competency and vital values towards sustainable achievement of their future. The key strategy of the succession plan is to mould and harness the talent of professional work force at academic leadership level to fill in strategic positions. The plan aids in the career path and laid foundation of guidance necessary for the accomplishment of tasks and duties of the future, in particular, academicians as research leaders.

\section{Leadership in Institutions of Higher Education}

Dynamic growth in the economic and educational sectors renders policy documentations and recent domestic debates in the country to continue to be galvanizing more efforts for quality in higher education. This has also pointed to the need for a shift in the growth trajectory with stronger emphasis on 'endogenous innovation' and 'harmonious development' as far as research initiative is concerned. It is imperative to define innovation here as the generation and application of ideas and skills to produce new product, process and service that improve economic and social prosperity in the society.

Malaysia is rapidly developing its own higher education innovative policy and infrastructure to ensure its competitiveness and continued growth in the global marketplace. This is imperative so as to make Malaysian institutions of higher education to the top 100 placing in the Times Higher Education Supplement (THES) Quacquarelli Symonds (QS) World University Rankings (WUR). This unprecedented move will have tertiary education be benchmarked against international standards and simultaneously, will enhance the quality of academics in terms of leadership, expertise and a sense of undivided commitment for educational excellence.

Through observation, it is pertinent to note that the shift in policy of a research university is towards research innovations, businesses and openness to establish an institutional setting of clear direction an institution needs to move towards, as far as research is concerned (Pfeffer \& Stutton, 2000). This initiative, together with other factors such as 
the presence of a high standard "Key Performance Index (KPI)" or "Sasaran Kerja Tahunan" (SKT) for all levels of academia, enhances significant research and development activities, in particular and learning and innovation in general. Subsequently, when there is a move to ensure excellent research leadership qualities, institutions of higher education will help to shape the institutional framework which in turn resulted in extremely high rates of capital accumulation, in research products and commercialisation.

In a more serious observation, it is clear that academic reputation of the faculty member based on refereed journal publication, working paper presentations, and academic networking at high impact world conventions, is the main factor that could help to propel efforts to enhance the quality of Malaysia's higher education system. A key component of research policy and innovative development is the assimilation and demand for high performance and innovative research that requires inspirational research leaders who publish research work in internationally renowned citation indexed or very high impact factor journals like Science or Nature.

Leaders of this calibre, develop collaborations with the top 10 universities in the world. Not only is their ability to contribute to rank respective institution through some of the often-cited global university ranking, but also to ensure that the institution graduates are in demand by some of the largest multinational companies, locally and overseas. Unnecessary campaigns like ISO, standardized teaching methods, long hourly meetings in faculties, competing for medals in international product competition, should not be the main focus of our Malaysian public universities as time, money and energy has long time been wasted and over-emphasized for nothing.

\section{The need for effective research leader}

Developing the research culture requires competent research leader. One has to be able to motivate academic staff and to lead them through change. (Blanchard \& Miller, 2007) This is a necessity as such an initiative helps academicians to be innovative in carrying out research process that eventually leads to research products and services. Research leader possesses ways of working creatively as research environment is ever changing, particularly in the new and challenging institution of higher education policy and innovation. Henceforth, knowledge-based research leader should be one who stewards protégé and mentee, be familiar with major concepts, theoretical perspectives, empirical findings, international outreach and historical trends in research leadership.

This leader needs also the knowledge and understanding of research leadership theories and skills. His application of leadership principles, in addition with the development of insights into his own leadership styles are vital (http://www.sedl.org/change/leadership/history.html). The application includes spiritual and ethical components as well as effective strategies for leadership of self and of others. Most importantly, being leaders, the capability in decision making and technology management in research has to be manifested with the ability to use legal, technical and decision-making knowledge for research purposes. Nevertheless, it is significant that such a leader utilizes a broad range of tools in research decision making practices.

\section{Internationalization and research leadership excellence}

To support the need of institution of higher education to move forward towards such excellence as Research or APEX University, academic and research exchanges with top notch world renowned universities abroad must be common in every field of study. Academic staff and researchers should often be sent abroad to acquire advanced $\mathrm{PhD}$ degrees or study specific fields of knowledge. Technical links with top 10 foreign universities like Harvard, Cambridge, Stanford, Yale, MIT and Oxford to do joint research in advanced and innovative technology can be materialized via efficient top-most stewardship of the institute. Expansion of such links allows local university's research leaders to improve their industrial capabilities faster, and subsequently, incorporate highly trained personnel who have professional connections to research institutions. More of our well reputable Malaysian Professors should be given an opportunity to be attached abroad as Visiting Professors or Scholars with sufficient funds supported by the government.

Moreover, cooperative research agreement between institutions of higher education and foreign firms should be a source of funds, infrastructure and commercial technology for local research leaders. Foreign firms usually bring the necessary research and technology. Strategic technical alliances with other world market leaders allow research leaders to penetrate new markets faster and give them access to a broader range of cutting-edge technology (Smith, 1996). Strategic cooperation is the process of identifying gaps in endogenous research and technologies, seeking out the technology, and then engaging the owner of the technology in a cooperative relationship that results in the transfer in technology.

In another advantage, such a co-operation can also include participation in joint international research. As the initial focus of this research is pre-competitive, start up institution spin-off companies from high impact research should be more willing to share their technology. Sufficient research and development funding set aside for basic industrial technology development is being allocated for the joint research and development cooperation.

It is important to highlight that improvement of public funds management and the development of scientific community-based evaluation would largely increase the efficiency of knowledge production. This shift can actually be 
combined with a more intense communication with industry both in research and higher education. In a more global knowledge society, is also important to participate in international academic communities and to expose the academic research to international competition. Such changes would certainly increase the rate of return from the increased investment in research and development for the community in institutions of higher education.

High performance and innovative research in the institutions of higher education requires inspirational, authenticable and emerging young research leaders. This should work in tandem with the government's mission and vision to enhance the standard and quality of higher education. Public universities now have a pivotal role in establishing a country as an excellent research hub. However, evidence reveals significant shortages in research leadership skills that relating to creating a sense of vision in a fast changing research environment, motivating research staff and leading them through change, and being innovative in research products and services. The standards and quality of higher education must be well maintained in order for a particular institution to be globally recognized (Brennan et al, 1997).

There are several leadership theories in literature of which opinions are given on how one becomes an innovative research leader (Middlehurst, 1993). Trait, behavioural and contingency theories represent conventional approaches to leadership and have provided important foundations for research on the subject. Some traits of a good innovative research leader in the arts, sciences and technology are creativity, technical foundation, confidence, consultative but decisive, inspirational, visionary, leading by example, and high technical standards. Personal qualities include being ethical, caring, ready with deserved praises, clear but gentle criticism and most importantly, never hurting a team member or subordinate's confidence.

\section{Establishing research infrastructure and capacity}

Up-to-date research infrastructure and learning tools are essentials for a researcher to enhance the quality of the teaching, learning and research environment. With the latest technology tools for leadership in teaching, learning, research and career development, these kinds of support help to enhance the desired quality of research leadership. Together with this and an uncompromised usage of technology, Malaysian universities must recruit and retain to graduation, excellent and diverse undergraduates, graduates, and professional students and high impact research staff. Hiring and keeping the best researchers would lead towards successful commercialisation and business effectively (Anon, 2007). This will in turn enhance and better serve the Malaysian industry.

Strategic technical alliances with other world market research leaders allow participating universities to penetrate new markets faster and give them access to a broader range of cutting-edge technology. These cooperative efforts will enable spin-out Malaysian firms to move rapidly onto the national as well as world stage. Malaysian universities can provide any number of incentives for technology transfer, including funding commercialisation, providing plants and equipment, contributing other technology, or facilitating local market access. Strategic cooperation can also include participation in joint international research. In the long run, Malaysian universities will also engage in international R\&D projects in such fields as environment, energy and natural resources and expanding international education and training programmes.

\section{Conclusion}

In every aspiration, total commitment and concerted efforts from all parties are needed to ensure the successful development of innovative research leaders and research culture in Malaysian tertiary institutions. Not only academia plays an important role in ensuring success of Malaysian universities of international stature, but also the supportive environment within and outside the institutions. The "way forward" includes the internationalization of research innovation and competent leadership. The above areas discussed need the concerted effort of university leadership to champion those causes as they are policy and decision makers in such drives. In Malaysian public institutions of higher education, the position of the Deputy Vice Chancellor under the Research and Innovation portfolio executes an overall plan that can develop and enhance rich research culture through faculties, institutes, centres of excellence and units.

This article though is partly an account of a 'personal' experience of a Yale University Visiting Professor who experienced first-hand value of international academic exchange; proves to be of great value to Malaysian public service and universities, to fund potential research leaders to visit only the Top 10 world class foreign universities, research labs or institutes. Expanding links with these universities also allow Malaysian research leaders to improve their industrial capabilities and to employ highly trained personnel who have professional connections to research institutions. A joint initiative by Malaysia Academy of Science's Brain Gain Malaysia (BGM) and the Ministry of Science, Technology \& Innovation (MOSTI)'s initiative is one of the good examples. Perhaps, MOHE should be deeply associated with its own programme to ensure that Malaysian institutions of higher education get listed in the Top 100 World Ranking Universities in 2020, if proper measures highlighted in this article are given due consideration.

\section{References}

Anon. (2007). Hiring and Keeping the Best People. Harvard Business Essentials. Your Mentor and Guide to doing Business Effectively. 
Blanchard, K. \& Mark, M. (2007). The Secret What Great Leaders Know and Do. San Francisco: Berrett-Koehler Publishers Inc.

Boettcher, S. \& Annette, C. (2008). Succession Planning for Higher Education CIOS_What Why How , San Antonio: UT Health Science Center.

Brennan, J., P. de Vries, and R. William. (1997). Standards and Quality in Higher Education. London: Jessica Kingsley Publishers.

Carey, D. C., D. Ogden \& J. A. Roland. (2000). CEO Succession. New York: Oxford University Press.

Carucci, R.A. (2007). Leadership Divided What emerging Leaders Need and What You Might be Missing. Jossey-Bass : A Wiley Imprint.

Coxhead, P. (2007). Academic Manager Job Description. University of Birmingham (Computer Science) 9 August 2002. 4 July $2008<$ http://www.cs.bham.ac.uk/ pxc/pers/jobspec.html $>(2007)$.

Derman, E. (2004). My Life as A Quant: Reflections on Physics and Finance, Wiley (2004) ISBN 0471394203 (also available in paperback, ISBN 0470192733) Excerpt of My Life as a Quant in Financial Engineering News (September 2004). http://www.ederman.com._Accessed on 28 October 2008.

Ella, Krishna (2006) Creating biotech talent pool The Business of Biotech Business Spectrum Bharat Biotech http://www.bharatbiotech.com/2006_mar06_2.htm Accessed on 16 November 2008.

Eastman, L.J. (1995). Succession Planning: An Annotated Bibliography and Summary of Commonly Reported Organisational Practices. Greensboro, North Carolina: Centre for Creative Leadership.

Evans, G. R. C. (1999). Academia to Account: Rights and Responsibilities. Buckingham, UK: Open University Press and The Society for Research into Higher Education.

Fulmer, R. M. and Jared L. B. (2008). Strategic Leadership Part 1: Applying Lessons Learned from Research about Strategic leadership Development. Pepperdine University Graziadio Shool of Business and Management 27 August 2008. <http://gbr.pepperdine.edu/072/leadership.html>

George, B. (2007). True North. Discover Your Authentic Leadership. Bill George with Peter Sims. Foreword by David Green. John Wiley and Sons.

Groves, K. S. (2007). Intergrating Leadership Development and Succession Planning Best Practices. Journal of Management Development, 26(3), 239-260.

Hamel, G.(2007). What Does the Future of Management Look Like to You? Posted on September 26, 2007 11:39 AM. http://discussionleader.hbsp.com/hamel/2007/09/what_does_the_future_of_manage.html.

Lindsey, R. R \& Schachter, B. (2007). How I became a Quant. John, Wiley \& Sons, Inc. Preis inkl. Mehrwertsteuer zzgl. Versandkosten.

Southwest Educational Development Laboratory-SEDL Leadership Change. Leadership characteristics that facilitate school change. http://www.sedl.org/change/leadership/history.html. (Accessed on 29 October 2008).

Kamaruzaman Jusoff. (2007). Research Leadership: Innovation and Policy from the Perspective of a Research University. An Invited Paper/Lecture presented at the ILQaM's TK5 Course, 10 ${ }^{\text {th }}$. December 2007, iLQaM's Auditorium 1, $3^{\text {rd }}$.Floor, Universiti Teknologi MARA, UiTM Shah Alam, Selangor, Malaysia. 13p.

Kamaruzaman Jusoff \& Siti Akmar Abu Samah. (2008a). Enhancing Malaysian Innovative Research Leadership from an Experiential Perspective. Commonwealth Innovations Building Networks for Better Governance. CAPAM Ottawa Vol. 14, No. 2 (2008a).

Kamaruzaman Jusoff \& Siti Akmar Abu Samah. (2008b). Innovative Leadership in Research Drive at Institutions of Higher Education.. Kementerian Pengajian Tinggi Malaysia BITARA Bil. 1 (2008b).

Mehrling, P. (2005). Fischer Black and the Revolutionary Idea of Finance. John, Wiley and Sons, Inc, Hoboken, New Jersey, USA

Middlehurst, R. (1993). Leading Academics. Buckingham, UK: Open University Press and The Society for Research into Higher Education.

Rosse, J. G. and R. A. Levin. (2003). Academic Administrator's Guide to Hiring-Between the Lines. San Francisco : Jossey-Bass.

Rothwell, W. J. (2005). Effective Succession Planning: Ensuring Continuity and Building Talent from Within $3^{\text {rd }}$ Edition. United States: American Management Association (AMACOM).

University of South Florida Polytechnic (2007). 3433 Winter Lake Road, Lakeland, FL 33803 taken from 
http://www.lakeland.usf.edu/polytechnic.html retrieved on 4 September 2008.

Universiti Teknologi MARA (2008). Vice Chancellor Circular Number 24/2008 dated 13 August 2008.

Vise, D. A. (2005). The Google Story: An Excerpt. http:/www.washingtonpost.com/wp-dyn/content/article/2005/11/11/AR2005111100674.html (Accessed on 07 November 2008).

Vise, D. A \& Malseed, M. (2006). The Google Story. Bantam Dell Publishing Group. http://www.randomhouse.com/catalog/display.pperl?isbn=9780739321621 (Accessed on 07 November 2008)

Wolfred, T. (2008).Building Leaderful Organisations: Succession Planning for Nonprofits. Baltimore, Maryland: The Anne E. Casey Foundation.

Zaini Abdullah, Siti Akmar Abu Samah, Kamaruzaman Jusoff \& Posiah Mohd Isa. (2008). Succession Planning in Malaysian Institution of Higher Education. International Education Studies Journal.Vol.2, No. 2, April 2009 (In Press). 